\title{
Veno-occlusive disease in children and adolescents after hematopoietic stem cell transplantation: Did the Modified Seattle Criteria fit the characteristics of pediatric population?
}

\author{
Zofia Szmit ${ }^{A-F}$, Ewa Gorczyńska ${ }^{\mathrm{A},-\mathrm{F}}$, Monika Mielcarek-Siedziuk ${ }^{\mathrm{A}, \mathrm{E}, \mathrm{F}}$, \\ Marek Ussowicz ${ }^{\mathrm{A}, \mathrm{E}, \mathrm{F}}$, Joanna Owoc-Lempach ${ }^{\mathrm{A}, \mathrm{B}, \mathrm{E}, \mathrm{F}}$, Krzysztof Kałwak ${ }^{\mathrm{A}, \mathrm{C}-\mathrm{F}}$ \\ Department of Pediatric Hematology/Oncology and Bone Marrow Transplantation, Wroclaw Medical University Supraregional Center \\ of Pediatric Oncology "Cape of Hope", Poland \\ A - research concept and design; $\mathrm{B}$ - collection and/or assembly of data; $\mathrm{C}$ - data analysis and interpretation; \\ $D$ - writing the article; $E$ - critical revision of the article; $F$ - final approval of the article
}

Address for correspondence

Zofia Szmit

E-mail:zofia.lutrowicz@gmail.com

Funding sources

None declared

Conflict of interest

None declared

Received on May 20, 2019

Reviewed on May 30, 2019

Accepted on December 4, 2019

Published online on March 24, 2020

Cite as

Szmit Z, Kałwak K, Mielcarek-Siedziuk M, Ussowicz M, Owoc-Lempach J, Gorczyńska E. Veno-occlusive disease in children and adolescents after hematopoietic stem cell transplantation: Did the Modified Seattle Criteria fit the characteristics of pediatric population? Adv Clin Exp Med. 2020:29(3):339-344. doi:10.17219/acem/115070

DOI

10.17219/acem/115070

Copyright

Copyright by Author(s)

This is an article distributed under the terms of the

Creative Commons Attribution 3.0 Unported (CC BY 3.0)

(https://creativecommons.org/licenses/by/3.0/)

\section{Abstract}

Background. Hepatic veno-occlusive disease (VOD) is a life-threatening complication following hematopoietic stem cell transplantation (HSCT) and associated with a high mortality rate. Therefore, accurate and immediate diagnosis is crucial for implementing appropriate treatment.

Objectives. In our single-center retrospective study, we assessed the accuracy of the Modified Seattle Criteria in children and adolescents undergoing HSCT, and compared them to the diagnostic criteria recently established by the European Society for Blood and Marrow Transplantation (EBMT).

Material and methods. Retrospective analysis of medical records of 951 HSCT procedures performed in 850 children and young adults in the years 2001-2015 in the Department of Pediatric Hematology, Oncology and Bone Marrow Transplantation of Wroclaw Medical University Supraregional Center of Pediatric Oncology "Cape of Hope" in Wrocław, Poland.

Results. Among the 850 children, 48 were diagnosed with VOD according to the Modified Seattle Criteria (5.05\%). Thirteen patients (27\%) developed VOD later than within 20 days after transplantation, as required in the diagnostic criteria. Five of the 6 patients who died from VOD were diagnosed with late-onset VOD. Using the categories of symptoms described in the Modified Seattle Criteria, hepatomegaly and weight gain were the most common symptoms in the analyzed cohort (81.25\% and 68.75\%). Fourteen patients (29\%) never demonstrated elevated plasma bilirubin level (>2 mg/dL), as suggested in the Modified Seattle Criteria. Twenty-nine patients (64\%) had increased platelet consumption requiring daily transfusions. Only 5 patients with decreased plasma antithrombin III (ATIII) activity level (<80\%) on the day of HSCT developed VOD despite supplementation of ATIII.

Conclusions. The Modified Seattle Criteria seemed to not meet the special needs of the pediatric population. The new diagnostic criteria proposed by the EBMT appear to be more adequately tailored to the pediatric population and may significantly change the conception of VOD in the future. The surprisingly low incidence of VOD in our cohort may suggest a beneficial role of monitoring and early supplementation of ATIll.

Key words: hematopoietic stem cell transplantation, pediatric, veno-occlusive disease 


\section{Introduction}

Hematopoietic stem cell transplantation (HSCT) has been used as a curative therapy for various kinds of disorders, both malignant and nonmalignant. Despite the increasing rate of successful transplantation procedures, the widespread use of the treatment is limited by concerns of life-threatening complications.

Hepatic veno-occlusive disease (VOD), also known as sinusoidal obstructive syndrome (SOS), is frequent and may be one of the most severe complications in the early postHSCT period. This syndrome is characterized by clinical features like rapid weight gain, ascites, painful hepatomegaly, and jaundice. ${ }^{1}$ Clinical suspicion of VOD may be supplemented by noninvasive imaging, such as ultrasonography (USG), particularly to identify attenuated or reversed hepatic venous flow, a typical USG finding in VOD. ${ }^{2,3}$ However, none of the diagnostic criteria, laboratory tests or USG findings are specific to VOD. Its incidence in the adult population historically has been reported in up to $60 \%{ }^{1,4-6}$ of patients undergoing HSCT, but nowadays it appears to be $13.7 \%$, with values ranging from $0 \%$ to $60.2 \%$ in different studies. ${ }^{7}$ Such great range of results depends on the diagnostic criteria used - the Baltimore or the Seattle Criteria (Table 1). ${ }^{6,8}$ In the face of the newly presented European Society for Blood and Marrow Transplantation (EBMT) diagnostic criteria for VOD in both the adult and pediatric population, the prevalence of this complication may change significantly in upcoming years (Table 2). ${ }^{9,10}$

Several risk factors for the development of VOD have been identified and inclusion of patients with each of these risk factors has differed between studies. The most widely accepted risk factors are allogeneic HSCT, previous liver disease, history of abdominal radiation, advanced disease (beyond the $2^{\text {nd }}$ complete remission or relapse) and busulfanand cyclophosphamide-based regimens. ${ }^{4,7,11}$ In the pediatric population, low body weight, low albumin level, autologous HSCT for neuroblastoma, younger age, some underlying diseases (i.e., hemophagocytic lymphohistiocytosis (HLH) and osteopetrosis) and previous treatment (i.e., eculizumab, gemtuzumab ozogamicin) were identified as specific risk factors for VOD. ${ }^{12-15}$ The severity of VOD could be retrospectively classified as mild, moderate or severe based on the dysfunction of the liver and associated organs.

Table 1. Comparison of Baltimore and Modified Seattle VOD Diagnostic Criteria

\begin{tabular}{|l|l|}
\hline \multicolumn{1}{|c|}{ Modified Seattle Criteria } & \multicolumn{1}{c|}{ Baltimore Criteria } \\
\hline $\begin{array}{l}\text { Two of following } \\
\text { occurring within 21 days } \\
\text { of transplantation: }\end{array}$ & $\begin{array}{l}\text { Bilirubin serum level }>2 \mathrm{mg} / \mathrm{dL} \text { and } \\
\text { at least 2 of following within 20 days } \\
\text { of transplant: }\end{array}$ \\
$\begin{array}{l}\text { hepatomegaly or right upper } \\
\text { quadrant pain } \\
\text { bilirubin serum level }>2 \mathrm{mg} \% \\
\begin{array}{l}\text { unexplained weight gain }>2 \% \\
\text { from baseline }\end{array}\end{array}$ & hepatomegaly \\
\hline
\end{tabular}

Table 2. European Society for Blood and Marrow Transplantation (EBMT) diagnostic criteria for hepatic VOD/SOS in children

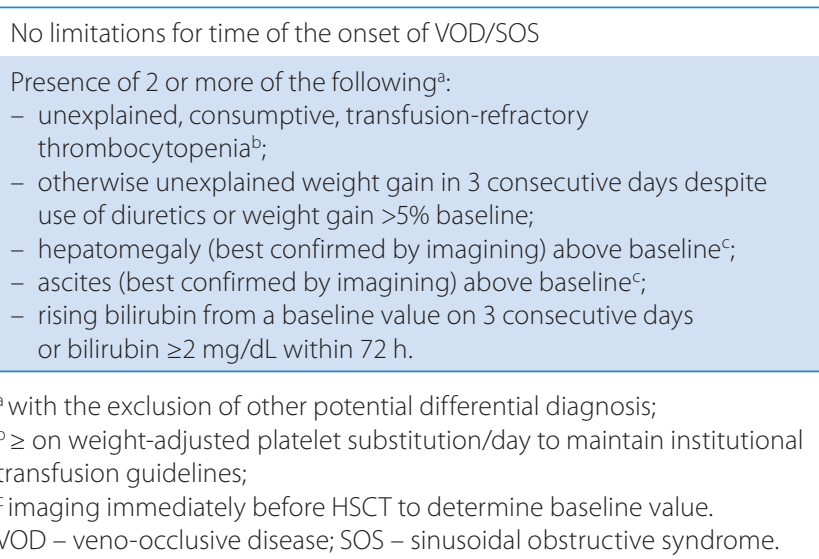

In addition to the recently proposed diagnostic criteria, the EBMT has established a new severity classification that would affect the structure of VOD incidence in transplant populations. ${ }^{9}$ Therapy options for VOD are still very limited and defibrotide is the only drug approved by both the European Union and the USA for VOD treatment. Many previous and ongoing trials provide promising results about the safety and efficacy of defibrotide as a crucial agent in both prophylaxis and treatment regimens for VOD. ${ }^{16-20}$ Additional treatment and prophylactic strategies using other agents such as heparin, antithrombin III, prednisone, or ursodiol have been studied, but none of them have been proven unequivocally effective. ${ }^{21-25}$

Given the limited number of large cohort studies on VOD in the pediatric population, in our single-center retrospective study, we have reported detailed VOD characteristics in children. In our research, we have evaluated the usefulness of the Modified Seattle Criteria, which have been widely used for over 25 years, particularly compared to the recently published EBMT VOD criteria in the pediatric population. We have also assessed the influence of antithrombin III (ATIII) supplementation on the prevalence of VOD in our center.

\section{Material and methods}

We retrospectively analyzed the medical records of 951 HSCT procedures performed on 850 children and young adults in the years 2001-2015 in the Department of Pediatric Hematology, Oncology and Bone Marrow Transplantation of Wroclaw Medical University Supraregional Center of Pediatric Oncology "Cape of Hope" in Wrocław, Poland. Seven hundred sixty-two patients underwent a single HSCT procedure, 76 patients required 2 HSCTs, 3 HSCTs were performed in 10 patients, and 4 HSCTs in 2 patients. Among the 951 transplantations performed, 246 were autologous and 705 were allogeneic. Among the allo-HSCTs, the stem cells were derived from bone marrow in 236 cases and from peripheral blood in 451 cases. Eighteen patients 
Table 3. Characteristic of study cohort

\begin{tabular}{|l|c|}
\hline \multicolumn{1}{|c|}{ Parameter } & Value \\
\hline HSCT analyzed & 951 \\
autologous & 246 \\
allogeneic & 705 \\
\hline Patients & 850 \\
after 1 transplantation & 762 \\
after 2 transplantations & 76 \\
after 3 transplantations & 10 \\
after 4 transplantations & 2 \\
Male/female & $534 / 316$ \\
\hline Age & 3 months-21 years (median: 8.87 years) \\
Stem cells source & \\
bone marrow & 237 \\
peripheral blood & 696 \\
cord blood unit & 18 \\
\hline Donor characteristic & \\
autologous & 246 \\
MSD & 184 \\
MUD & 420 \\
MMUD & 101 \\
\hline
\end{tabular}

MSD - matched sibling donor; MUD - matched unrelated donor; MMUD - mismatched unrelated donor.

Table 4. Indications for HSCT in study cohort

\begin{tabular}{|c|c|c|c|}
\hline \multicolumn{2}{|c|}{ Diagnosis } & \multicolumn{2}{|c|}{ Number of patients } \\
\hline $\begin{array}{l}\text { Hematological } \\
\text { malignancies }\end{array}$ & $\begin{array}{l}\text { ALL } \\
\text { AML } \\
\text { CML } \\
\text { MDS } \\
\text { LYM }\end{array}$ & $\begin{array}{r}227 \\
125 \\
36 \\
65 \\
53\end{array}$ & total $n=506$ \\
\hline Anemias & $\begin{array}{l}\text { SAA } \\
\text { BDA } \\
\text { FA }\end{array}$ & $\begin{array}{l}62 \\
10 \\
13\end{array}$ & total $n=85$ \\
\hline Solid tumors & $\begin{array}{c}\text { neuroblastoma } \\
\text { Ewing sarcoma } \\
\text { other }\end{array}$ & $\begin{array}{r}100 \\
40 \\
35\end{array}$ & total $n=175$ \\
\hline $\begin{array}{l}\text { Immuno- } \\
\text { deficiencies }\end{array}$ & $\begin{array}{c}\text { SCID } \\
\text { X-CGD } \\
\text { Omenn syndrome } \\
\text { other }\end{array}$ & $\begin{array}{r}26 \\
11 \\
8 \\
21\end{array}$ & total $n=66$ \\
\hline $\begin{array}{l}\text { Metabolic } \\
\text { disorders }\end{array}$ & $\begin{array}{l}\text { ALD } \\
\text { MLD } \\
\text { other }\end{array}$ & $\begin{array}{l}7 \\
2 \\
9\end{array}$ & total $n=18$ \\
\hline
\end{tabular}

$\mathrm{ALL}$ - acute lymphoblastic leukemia; $\mathrm{AML}$ - acute myeloblastic leukemia; CML - chronic myeloid leukemia; MDS - myelodysplastic syndrome; LYM - lymphoma; SAA - severe anaplastic anemia; BDA - Blackfan-Diamond anemia; FA - Fanconi anemia; SCID - severe congenital immunodeficiency; X-CGD - chronic granulomatous disease; ALD - adrenoleukodystrophy; MLD - metachromatic leukodystrophy.

received stem cells from a cord blood unit. The complete clinical and demographic analysis of the patient cohort is presented in Tables 3 and 4.

\section{Definitions}

Each case of VOD was diagnosed using the Modified Seattle Criteria, which requires at least 2 of the following clinical findings within 20 days of transplantation: painful hepatomegaly, weight gain $>2 \%$ above baseline and plasma bilirubin level $>2 \mathrm{mg} / \mathrm{dL}$ ( $34 \mathrm{mcmol} / \mathrm{L})$. The severity was evaluated on the basis of criteria proposed by McDonald et al. ${ }^{1}$ : mild for cases that resolved spontaneously, moderate when treatment was required but the symptoms were resolved completely and severe when there was associated multiorgan failure (MOF) or the symptoms were not resolved by day 100 post-HSCT.

\section{Prophylaxis and treatment}

Every patient was scheduled for careful ATIII activity monitoring, starting from the first day of conditioning. Measurements of ATIII were repeated twice a week and continued till day 100 post-HSCT. If a patient developed low levels of ATIII, its activity was measured more often, i.e., every day.

Every patient who demonstrated decreased plasma ATIII activity in the period between the beginning of the conditioning up to 100 days post-HSCT received an additional supplementation of ATIII to maintain its activity over $80 \%$. The treatment strategies for patients with confirmed VOD depended on the severity of the symptoms and any coexisting multiorgan failure. They varied from conservative measures such as fluid restriction and ursodiol in mild cases up to combined treatment with defibrotide (daily dose $25 \mathrm{mg} / \mathrm{kg}$ b.w.) and additional diuretics, anticoagulant agents and multiple platelets transfusions.

\section{Results}

Veno-occlusive disease was diagnosed in 48 patients -20 females and 28 males. Forty-seven patients developed VOD after the $1^{\text {st }}$ HSCT. There was only 1 case of VOD following consecutive transplantation. Patients were from 7 months to 19.5 years of age at the time of HSCT. Venoocclusive disease developed in 26 of the 246 autologous HSCT recipients (10.6\%) and in 22 of the 705 allogeneic HSCT recipients (3.1\%). Mild VOD occurred in 7 patients (14.6\% of VOD), and severe occurred in 39 patients (81.25\% of VOD). Two patients developed moderate VOD. The overall incidence of VOD in the study cohort was $5.05 \%$. There was a significantly higher difference in VOD incidence when the analyzed autologous HSCT was compared to allogeneic HSCT $(\mathrm{p}<0.05)$. The indications for transplant in the VOD cohort was most commonly solid tumors (26 patients), mainly neuroblastoma. Conditioning regimens, as a well-known risk factor for VOD, were also assessed. All patients, except for one, who were diagnosed with VOD, received a myeloablative regimen prior to HSCT. The majority of patients (38) received busulfan/ melphalan, while 9 received a TBI-based regimen (Table 5).

Time from HSCT to VOD onset varied between 3 days to 67 days post-transplantation (median: 14.5 days). Cases of VOD diagnosed after 20 days post-transplantation (13 patients, 27\%) were confirmed by the presence of specific 
Table 5. Detailed characteristic of VOD patients

\begin{tabular}{|c|c|c|}
\hline \multicolumn{2}{|c|}{ Parameters } & Values \\
\hline \multirow{2}{*}{ Sex } & male & 28 \\
\hline & female & 20 \\
\hline \multirow[b]{2}{*}{$\begin{array}{l}\text { Type of transplant } \\
\text { and donor }\end{array}$} & AUTO & 26 \\
\hline & $\begin{array}{l}\text { ALLO: } \\
\text { MSD } \\
\text { MUD } \\
\text { MMUD }\end{array}$ & $\begin{array}{r}22 \\
6 \\
13 \\
3\end{array}$ \\
\hline \multirow{2}{*}{ Stem cells source } & bone marrow & 7 \\
\hline & peripheral blood & 41 \\
\hline \multirow[t]{2}{*}{$\begin{array}{l}\text { Conditioning } \\
\text { regimen }\end{array}$} & $\begin{array}{l}\text { MAC: } \\
\text { TBI } \\
\text { BU-MEL } \\
\text { MEC }\end{array}$ & $\begin{array}{r}47 \\
9 \\
36 \\
2\end{array}$ \\
\hline & $\mathrm{RIC}$ & 1 \\
\hline \multirow{6}{*}{ Diagnosis } & $A L$ & 16 \\
\hline & CML & 1 \\
\hline & IE & 1 \\
\hline & ID & 1 \\
\hline & LYM & 3 \\
\hline & $\begin{array}{l}\text { solid tumor: } \\
\text { NBL } \\
\text { Ewing } \\
\text { Yolk sac } \\
\text { Wilms }\end{array}$ & $\begin{array}{r}26 \\
20 \\
4 \\
1 \\
1\end{array}$ \\
\hline \multirow{2}{*}{$\begin{array}{l}\text { Staging at the } \\
\text { moment of HSCT }\end{array}$} & advanced & 40 \\
\hline & non-advanced & 8 \\
\hline Age [years] & \multicolumn{2}{|c|}{ range: 0.6-19.5, median: 6.75} \\
\hline
\end{tabular}

AUTO - autologous transplantation; ALLO - allogeneic transplantation; MSD - matched sibling donor; MUD - matched unrelated donor;

MMUD - mismatched unrelated donor; MAC - myeloablative conditioning; TBI - total body irradiation 12 Gy; BU-MEL - busulfan (16-19 mg/kg)+ melphalan $\left(140 \mathrm{mg} / \mathrm{m}^{2}\right)$-based regimen; $\mathrm{RIC}$ - reduced intensity regimen; RTC - reduced toxicity regimen (Busulfan (9-12 mg/ $\mathrm{kg}$ )+Fludarabine $\left.150 \mathrm{mg} / \mathrm{m}^{2}\right)$; MEC - Melphalan (140 mg/m²)+Etoposide (60 mg/kg) conditioning regimen; $\mathrm{AL}$ - acute leukemia; IE - metabolic disorders; ID - immunodeficiency; LYM - lymphoma; NBL - neuroblastoma. Non-advanced disease - 1CR (1 ${ }^{\text {st }}$ complete remission); CML - chronic phase, non-malignant disease; advanced - anything below non-advanced.

findings in an abdominal USG such as attenuated or even reversed blood flow in the portal vein. Nine cases of lateonset of VOD were confirmed with liver biopsy.

Among the diagnostic criteria used in the Modified Seattle Criteria, hepatomegaly was most commonly observed in our patients ( $\mathrm{n}=39 ; 81.25 \%)$. Ascites and weight gain occurred accordingly in 32 (66.7\%) and 33 (68.75\%) patients. Plasma bilirubin level range at diagnosis was $0.7-32.5 \mathrm{mg} / \mathrm{dL}$ (median $2.83 \mathrm{mg} / \mathrm{dL}$ ). Fourteen patients (29\%) never demonstrated a bilirubin level higher than $2 \mathrm{mg} / \mathrm{dL}$, as indicated in the Modified Seattle Criteria, neither on the day of diagnosis nor during the course of treatment for VOD.

In the entire study cohort, $19 \%$ of patients $(n=181)$ demonstrated decreased ATIII activity level on day 0 and received immediate ATIII supplementation. Antithrombin III activity range on day 0 was $44-152 \%$ (median: $101 \%)$. Only
5 patients, among those who demonstrated decreased ATIII levels on the day of HSCT, developed VOD, despite being given prophylaxis. In the VOD cohort, 10 patients (21\%) had normal ATIII activity levels since the beginning of pre-HSCT conditioning through the resolution of symptoms of VOD (9 patients) or death (1 patient). The remainder of patients that were diagnosed with VOD $(n=33,68.8 \%)$ developed decreased ATIII plasma activity between 19 days prior, up to the day of diagnosis of VOD (median: 3 days before diagnosis of VOD).

Twenty-nine patients (64\%) demonstrated increased platelet consumption followed by refractory thrombocytopenia and required daily platelet transfusions to maintain transfusion criteria (platelet count below 20,000/mcL).

Resolution of VOD symptoms was defined as platelet level sustainability and platelet transfusion independence, resolution of painful hepatomegaly, resolution of jaundice, and reduction of ascites (which was measured by a decrease of waist circumference to the patient's baseline as well as weight reduction). Using this definition, duration of VOD symptoms ranged from 3 to 47 days (median: 19 days). Eight patients (16.6\%) died before the resolution of symptoms.

During therapy, 29 patients $(60.4 \%)$ with VOD received defibrotide. The response rate for defibrotide was $82.76 \%$. The time of treatment ranged from 4 days to 26 days (median: 12 days). Each patient was given a standard dose of $25 \mathrm{mg} / \mathrm{kg}$ b.w. daily.

Day 100 mortality rate in the VOD cohort was $21 \%$ $(\mathrm{n}=10)$, compared to the $15.52 \%(\mathrm{n}=132)$ day 100 mortality rate in the entire cohort of patients. In the VOD cohort, 10 more patients died after day 100 but their causes of death were not directly related to the HSCT.

Day 100 mortality rate among patients treated with defibrotide was $17 \%(n=5)$. Veno-occlusive disease was recognized as the cause of death in 6 patients (12.5\%). Two more patients died from septic shock and gastrointestinal hemorrhage with coexisting active VOD. Importantly, only 1 patient among those who died of VOD was diagnosed within 20 days post-HSCT. Detailed cause-of-death information is presented in Table 6 .

Table 6. Causes of day +100 transplant-related mortality in veno-occlusive disease (VOD) cohort

\begin{tabular}{|l|c|}
\multicolumn{1}{|c|}{ Cause of death } & $\mathrm{n}=10$ \\
\hline VOD & 6 \\
\hline Infection & 3 \\
Hemorrhage & 1 \\
\hline
\end{tabular}

\section{Discussion}

The incidence of VOD in our study was $5.05 \%$. Other publications that have also focused strictly on VOD in children have reported incidence ranges from $13 \%$ to $28 \% .^{12-15,26-30}$ This high variability in rates of VOD might be caused by the selected study cohort, different risk factors and, of course, ambiguous diagnostic criteria. 
However, in light of the recently implemented diagnostic criteria, the incidence of VOD in the pediatric population may shift drastically. The most recent research conducted by Corbacioglu et al. ${ }^{9}$ demonstrates major differences in VOD prevalence depending on the criteria used, suggesting that VOD may be more common than previously thought. Given the criteria proposed by EBMT, there is also a possibility that VOD was underdiagnosed in our center, even taking into account 13 late-onset cases which did not meet the Modified Seattle Criteria.

Our study revealed that patients undergoing autologousHSCT more likely develop VOD than patients receiving allogeneic graft - $10.6 \%$ compared to $3.12 \%$. This result is quite opposite to those presented in the literature concerning adult patients, as allogeneic stem cell transplantation is a well-known risk factor for VOD in the adult population. There are only a few studies performed on very limited study cohorts (86 and 116 patients) analyzing VOD after autotransplantations in children. Those studies report an extremely high incidence of VOD, reaching 39\%. ${ }^{31,32}$ The difference in frequency of VOD after autologous and allogeneic transplantations presented in our analysis is most likely caused by the fact that almost all of the patients treated with autotransplantation were suffering from neuroblastoma, a known risk factor for VOD. ${ }^{32}$ The exact mechanism for this increased risk in neuroblastoma is not known, but it likely relates to the association with other known VOD risk factors such as previous abdominal radiation, specific chemotherapy agents including tandem transplantations and lower albumin level prior to HSCT. ${ }^{32}$

The majority of patients in our VOD cohort were recipients of a $1^{\text {st }} \mathrm{HSCT}$. Only 1 out of 88 patients receiving multiple transplants developed VOD. This observation may indicate that it is not the cumulative doses of chemotherapeutic agents that are a risk factor for VOD, but rather the intensity of treatment in a limited period of time that has a significant impact, given that several other studies have found a correlation with increased risk following subsequent transplantation. ${ }^{13}$

The prevalence of late-onset VOD has never been properly assessed in the pediatric population. ${ }^{33}$ Several studies report a minority of VOD occurrences diagnosed later than 20 days post-transplantation. In our cohort, almost $1 / 3$ (27\%) of patients did not meet the time criterion of VOD required in the Modified Seattle Criteria. Our results are in compliance with the absence of time limitation in the newly proposed diagnostic criteria, where VOD may be diagnosed regardless of the time when the first symptoms occurred. This may be particularly important given the high mortality rate associated with late-onset VOD in our cohort. Five of the 6 patients who died of VOD in our cohort were diagnosed with late-onset VOD. New EBMT VOD criteria for adults (Mohty et al. ${ }^{10}$ ) have highlighted for the first time the presence of anicteric VOD. This phenomenon seems to be even more frequent in children, which has been emphasized by Corbacioglu et al. ${ }^{9}$
Fourteen patients (27\%) never demonstrated a bilirubin level over $2 \mathrm{mg} / \mathrm{dL}$, as suggested in the Modified Seattle or Baltimore VOD diagnostic norms. A similar percentage of anicteric patients were reported in other studies ${ }^{26,27}$; nonetheless, bilirubin level, even if not mandatory, still remained a part of the VOD diagnostic criteria. The novel approach to VOD emphasizes the importance of bilirubin kinetics, instead of bilirubin plasma levels alone. Although elevated bilirubin level is a common VOD symptom, lack of hyperbilirubinemia should not lead to a delay in diagnosis and treatment. As reported by Corbacioglu, ${ }^{16}$ the response to treatment with defibrotide is significantly lower when implemented more than 2 days from diagnosis. Therefore, a proper and immediate diagnosis, based on adequate criteria, is crucial for general patient outcome.

Bilirubin levels and its kinetics are suggested to be more a prognostic factor than a strict diagnostic criterion. ${ }^{9}$

Increased platelet consumption was a prominent feature of our VOD cohort. Sixty-four percent of patients required daily platelet transfusions to maintain adequate hematologic parameters. The median time of transfusion dependence related to VOD was 14 days. Even if mentioned in the very first studies about VOD, refractory thrombocytopenia (RT) has been overlooked as a VOD symptom for years. Despite not being a part of the diagnostic criteria, in our center, RT has remained an important symptom and diagnostic hint for VOD. Correlation of ATIII activity level and development of VOD is still unclear. Only half of patients demonstrated a sudden drop in ATIII activity, as indicated in previous studies. Even if such an evident drop was observed, it mostly happened only 3 days before a diagnosis was made. Haussmann et al. demonstrated an even shorter time lapse between ATIII activity decline and diagnosis of VOD. ${ }^{24}$ This makes plasma ATIII activity drop a poor prognostic factor for VOD. Although both Haussman and Peres emphasize a beneficial effect of early intervention with ATIII, ${ }^{24,25}$ it has never been highlighted in the major expert opinions. Looking at the relevantly lower incidence of VOD, this beneficial effect of ATIII supplementation seems to be confirmed by our study.

\section{Conclusions}

Veno-occlusive disease is a quite frequent, partially unexpected and potentially fatal complication following HSCT. New VOD diagnostic criteria provided by EBMT seem to be more adequate for the pediatric population than the recently used Modified Seattle Criteria. The newly proposed criteria correlate better with actual clinical findings in children diagnosed with VOD after HSCT. Removal of the time factor and hyperbilirubinemia, and incorporation of RT into the diagnostic criteria were crucial. The lower incidence of VOD in our center might suggest that early supplementation of ATIII to maintain its activity over $80 \%$ could be an efficacious prophylaxis against VOD. This novel finding requires further studies. 


\section{ORCID iDs}

Zofia Szmit (1) https://orcid.org/0000-0002-1069-9404

Krzysztof Kałwak (1) https://orcid.org/0000-0003-1174-5799

Monika Mielcarek-Siedziuk (10) https://orcid.org/0000-0003-2745-120X

Marek Ussowicz (1) https://orcid.org/0000-0001-5725-4835

Joanna Owoc-Lempach (10) https://orcid.org/0000-0001-7329-4079

Ewa Gorczyńska (1) https://orcid.org/0000-0002-5709-6731

\section{References}

1. McDonald GB, Hinds MS, Fisher LD, et al. Veno-occlusive disease of the liver and multiorgan failure after bone marrow transplantation: A cohort study of 355 patients. Ann Intern Med. 1993;118(4):255-267.

2. Tasu JP, Rocher L, Péletier G, et al. Hepatic venous pressure gradients measured by duplex ultrasound. Clin Radiol. 2002;57(8):746-752. doi:10.1053/crad.2002.0951

3. Brown P. Doppler sonography: A noninvasive method for evaluation of hepatic venocclusive disease. AJR Am J Roentgenol. 1990;154(4):712-724.

4. Carreras E, Díaz-Beyá M, Rosiñol L, Martínez C, Fernández-Avilés F, Rovira M. The incidence of veno-occlusive disease following allogeneic hematopoietic stem cell transplantation has diminished and the outcome improved over the last decade. Biol Blood Marrow Transplant. 2011;17(11):1713-1720. doi:10.1016/j.bbmt.2011.06.006

5. Bearman SI, Anderson GL, Mori M, Hinds MS, Shulman HM, McDonald GB. Venoocclusive disease of the liver: Development of a model for predicting fatal outcome after marrow transplantation. J Clin Oncol. 1993;11(9):1729-1736.

6. Jones RJ, Lee KS, Beschorner WE, et al. Venoocclusive disease of the liver following bone marrow transplantation. Transplantation. 1987; 44(6):778-783.

7. Coppell J, Richardson PG, Soiffer R, et al. Hepatic veno-occlusive disease following stem cell transplantation: Incidence, clinical course, and outcome. Biol Blood Marrow Transplant. 2010;16(2):157-168. doi:10.1016/j.bbmt.2009.08.024

8. Shulman HM, Hinterberger W. Hepatic veno-occlusive disease: Liver toxicity syndrome after bone marrow transplantation. Bone Marrow Transplant. 1992;10(3):197-214.

9. Corbacioglu S, Carreras E, Ansari M, et al. Diagnosis and severity criteria for sinusoidal obstruction syndrome/veno-occlusive disease in pediatric patients: A new classification from the European Society for Blood and Marrow Transplantation. Bone Marrow Tranplant. 2017;53(2):138-145. doi:10.1038/bmt.2017.161

10. Mohty M, Malard F, Abecassis M, et al. Revised diagnosis and severity criteria for sinusoidal obstruction syndrome/veno-occlusive disease in adult patients: A new classification from the European Society for Blood and Marrow Transplantation. Bone Marrow Transplant. 2016;51(7):906-912. doi:10.1038/bmt.2016.130

11. Mohty M, Malard F, Abecassis M, et al. Sinusoidal obstruction syndrome/veno-occlusive disease: Current situation and perspectives. A position statement from the European Society for Blood and Marrow Transplantation (EBMT). Bone Marrow Transplant. 2015;50(6):781-789. doi:10.1038/bmt.2015.52

12. Hasegawa S, Horibe K, Kawabe T, et al. Veno-occlusive disease of the liver after allogeneic bone marrow transplantation in children with hematologic malignancies: Incidence, onset time and risk factors. Bone Marrow Transplant. 1998;22(12):1191-1197.

13. Maximova N, Ferrara G, Minute M, et al. Experience from a single paediatric transplant centre with identification of some protective and risk factors concerning the development of hepatic veno-occlusive disease in children after allogeneic hematopoietic stem cell transplant. Int J Hematol. 2014;99(6):766-772. doi:10.1007/s12185-014-1578-y

14. Cheuk DKL, Wang P, Lee TL, et al. Risk factors and mortality predictors of hepatic veno-occlusive disease after pediatric hematopoietic stem cell transplantation. Bone Marrow Transplant. 2007;40(10): 935-944. doi:10.1038/sj.bmt.1705835

15. Lee $\mathrm{SH}$, Yoo KH, Sung KW, et al. Hepatic veno-occlusive disease in children after hematopoietic stem cell transplantation: Incidence, risk factors, and outcome. Bone Marrow Transplant. 2010;45(8):1287-1293. doi:10.1038/bmt.2009.349

16. Corbacioglu S, Greil J, Peters C, et al. Defibrotide in the treatment of children with veno-occlusive disease (VOD): A retrospective multicentre study demonstrates therapeutic efficacy upon early intervention.
Bone Marrow Transplant. 2004;33(2):189-195. doi:10.1038/sj.bmt. 1704494

17. Corbacioglu S, Carreras E, Mohty M, et al. Defibrotide for the treatment of hepatic veno-occlusive disease: Final results from the International Compassionate Use Program. Biol Blood Marrow Transplant. 2016;22(10):1874-1882. doi:10.1016/j.bbmt.2016.07.001

18. Dignan F, Gujral D, Ethell M, et al. Prophylactic defibrotide in allogeneic stem cell transplantation: Minimal morbidity and zero mortality from veno-occlusive disease. Bone Marrow Transplant. 2007;40(1):79-82. doi:10.1038/sj.bmt.1705696

19. Richardson PG, Ho VT, Giralt S, et al. Safety and efficacy of defibrotide for the treatment of severe hepatic veno-occlusive disease. Ther Adv Hematol. 2012;3(4):253-265. doi:10.1177/2040620712441943

20. Richardson PG, Riches ML, Kernan NA, et al. Phase 3 trial of defibrotide for the treatment of severe veno-occlusive disease and multiorgan failure. Blood. 2016;127(13):1656-1666. doi:10.1182/blood-201510-676924

21. Forrest DL, Thompson K, Dorcas VG, Couban SH, Pierce R. Low molecular weight heparin for the prevention of hepatic veno-occlusive disease (VOD) after hematopoietic stem cell transplantation: A prospective phase II study. Bone Marrow Transplant. 2003;31(12):1143-1149. doi:10.1038/sj.bmt.1704087

22. Imran H, Tleyjeh IM, Zirakzadeh A, Rodriguez V, Khan SP. Use of prophylactic anticoagulation and the risk of hepatic veno-occlusive disease in patients undergoing hematopoietic stem cell transplantation: A systematic review and meta-analysis. Bone Marrow Transplant. 2006;37(12):677-686. doi:10.1038/sj.bmt.1705297

23. Park SH, Lee MH, Lee $\mathrm{H}$, et al. A randomized trial of heparin plus ursodiol vs heparin alone to prevent hepatic veno-occlusive disease after hematopoietic stem cell transplantation. Bone Marrow Transplant. 2002;29(2):137-143. doi:10.1038/sj.bmt.1703342

24. Haussmann U, Fischer J, Eber S, Scherer F, Seger R, Gungor T. Hepatic veno-occlusive disease in pediatric stem cell transplantation: Impact of pre-emptive antithrombin III replacement and combined antithrombin III/defibrotide therapy. Haematologica. 2006;(6):795-800. doi:10.3324/haematol.13619

25. Peres E, Kintzel P, Dansey R, et al. Early intervention with antithrombin III therapy to prevent progression of hepatic venoocclusive disease. Blood Coagul Fibrinolysis. 2008;19(3):203-207. doi:10.1097/MBC. 0b013e3282f2b5d9.

26. Myers KC, Dandoy C, El-Bietar J, Davies SM, Jodele S. Veno-occlusive disease of the liver in the absence of elevation in bilirubin in pediatric patients after hematopoietic stem cell transplantation. Biol Blood Marrow Transpl. 2015;21(2):379-381. doi:10.1016/j.bbmt.2014.09.026

27. Naples JC, Skeens MA, Auletta J, et al. Anicteric veno-occlusive disease after hematopoietic stem cell transplantation in children. Bone Marrow Transplant. 2016;51(1):135-137. doi:10.1038/bmt.2015.208

28. Reiss U, Cowan M, McMillan A, Horn B. Hepatic venoocclusive disease in blood and bone marrow transplantation in children and young adults: Cohort of 241 patients. J Pediatr Hematol Oncol. 2002;24(9): 746-750.

29. Barker CC, Butzner JD, Anderson RA, Brant R, Sauve RS. Incidence, survival and risk factors for the development of veno-occlusive disease in pediatric hematopoietic stem cell transplant recipients. Bone Marrow Transplant. 2003;32(1):79-87. doi:10.1038/sj.bmt.1704069

30. Jevtic D, Zecevic Z, Veljkovic D, Dopsaj V, Radojicic Z, Elezovic I. Venoocclusive disease in pediatric patients after hematopoietic stem cell transplantation: Relevance of activated coagulation and fibrinolysis markers and natural anticoagulants. J Pediatr Hematol Oncol. 2011; 33(3):227-234. doi:10.1097/MPH.0b013e31820539fd

31. Cacchione A, LeMaitre A, Couanet DV, et al. Risk factors for hepatic veno-occlusive disease: A retrospective unicentric study in 116 children autografted after a high-dose BU-thiotepa regimen. BoneMarrow Transplant. 2008;42(7):449-454. doi:10.1038/bmt.2008.186

32. Horn B, Reiss U, Matthay K, McMillan A, Cowan M. Veno-occlusive disease of the liver in children with solid tumors undergoing autologous hematopoietic progenitor cell transplantation: A high incidence in patients with neuroblastoma. Bone Marrow Transplant. 2002; 29(5):409-415. doi:10.1038/sj.bmt.1703393

33. Toh HC, McAfee SL, Sackstein R, Cox BF, Colby C, Spitzer TR. Late onset veno-occlusive disease following high-dose chemotherapy and stem cell transplantation. Bone Marrow Transplant. 1999;24(8):891-895. 